\title{
Origen y funcionamiento hidrogeológico del único criptohumedal subhalófilo-alcalinófilo en la facies Guadalajara del acuífero Terciario detrítico de Madrid
} Hydrogeological origin and functioning of the unique alkaline
sub-halophyte crypto-wetland in Guadalajara detrital facies of
the Madrid Tertiary aquifer

\author{
M. Martín-Loeches Garrido ${ }^{1}$ J. Pavón García², M. García Martínez
}

1 Dep. de Geografía y Geología, Universidad de Alcalá, Edificio de Ciencias del Campus Universitario. Ctra. N-II, km. 33,600. 28871 Alcalá de Henares, Madrid. Email: miguel.martin@uah.es

2 Departamento de Ciencias de la Vida de la Universidad de Alcalá. Edificio de Ciencias del Campus Universitario. Ctra. N-II, km. 33,600. 28871 Alcalá de Henares, Madrid. Email: Javier.pavon@uah.es

3 C/ Coruña. 28805, Alcalá de Henares, Madrid. Email: manuel.garciam@outlook.es

\section{RESUMEN}

\begin{abstract}
El humedal de la Dehesa de Arriba perteneciente a Torrejón del Rey (prov. Guadalajara) es un criptohumedal dominado por un prado juncal subhalófilo-alcalinófilo no descrito hasta la fecha entre las zonas húmedas del acuífero terciario de Madrid. Se sitúa en la parte media de la cuenca terciaria del río Henares sobre la facies Guadalajara. Los procesos de evaporación son la causa de su notable diversidad en especies vegetales y de la aparición de eflorescencias alcalinas. Se parte de aguas subterráneas de escaso recorrido, del tipo $\mathrm{HCO}_{3}-\mathrm{Ca}$ y mineralización próxima a los $700 \mu \mathrm{S} / \mathrm{cm}$ que descargan $2 \mathrm{~km}$ al sur del punto de captura del arroyo Camarmilla por el río Torote. La morfología del humedal con depósitos de coluviones sobre los aluviales, juega un papel importante en la distribución de las especies vegetales y los salgüeros ya que determina la profundidad del nivel freático e influye en el alcance hasta la superficie del agua capilar. El drenaje de los suelos es escaso debido a la topografía y a la escasa incisión del río por su captura. Al humedal, que constituye hoy el nacimiento del arroyo Camarmilla, llegan anualmente $56.400 \mathrm{~m}^{3}$ de agua subterránea y sus suelos generan un excedente de $29.000 \mathrm{~m}^{3}$ entre diciembre y mayo en años medios. La alcalinidad es elevada en cualquier zona, siendo mayor en las áreas con praderas dominadas por gramíneas y ciperáceas de bajo porte y máxima en los salgüeros con un $\mathrm{pH}$ de 10.3 y una concentración de $\mathrm{Na}^{+}$en su solución de $2871 \mathrm{mg} / \mathrm{l}$. Los procesos de formación de este enclave y su posición en el contexto hidrogeológico general, elevan este humedal a singular de entre los que se sitúan en el acuífero de Madrid, constituyendo un paraje único en la provincia de Guadalajara y en la región de Castilla-La Mancha.
\end{abstract}

Palabras clave: Humedal; acuífero de Madrid; cuenca media del río Henares; plantas indicadoras; hidrogeología; eflorescencias alcalinas; evaporación.

Recibido el 16 de diciembre de 2014 / Aceptado el 21 de mayo de 2015 / Publicado online el 06 de noviembre de 2015

Citation / Cómo citar este artículo: M. Martín-Loeches Garrido, J. Pavón García \& M. García Martínez (2015). Origen y funcionamiento hidrogeológico del único criptohumedal subhalófilo-alcalinófilo en la facies Guadalajara del acuífero Terciario detrítico de Madrid. Estudios Geológicos 71(2): e037. http://dx.doi.org/10.3989/egeol.41989.356.

Copyright: ( $\odot 2015$ CSIC. This is an open-access article distributed under the terms of the Creative Commons Attribution-Non Commercial (by-nc) Spain 3.0 License. 


\section{ABSTRACT}

Dehesa de Arriba wetland is a subhalofite-alkalinofite reed meadow so far not described among the Madrid tertiary aquifer wetlands. Is located in the medium-high area of Henares river tertiary basin. The evaporation phenomena are the reason of its diversity and the presence of alkaline efflorescence. The water in origin is the discharge of small evolve groundwater, of the type $\mathrm{HCO}_{3}-\mathrm{Ca}$ and mineralization of $700 \mu \mathrm{S} / \mathrm{cm}, 2 \mathrm{~km}$ southward from the point where Camarmilla is captured by Torote river. The morphology of the wetland play an important role in the distribution of the species and the alkaline efflorescence since determine the phreatic level depth and affects the extent of capillary water up to the surface. The drainage of the soils in scarce because the smooth topography and the small erosion of the river after its capture. To the wetland, that is now the born of the Camarmilla stream, arrives $56.400 \mathrm{~m}^{3}$ of groundwater annually and its soils generate a surplus of $29.000 \mathrm{~m}^{3}$ from december to may in average years. The alkalinity is high in any area, although is higher in the graminoids and cyperaceous zones and is the highest in the efflorescence with a pH of 10.3 and a concentration of $\mathrm{Na}+$ in its solution of $2871 \mathrm{mg} / \mathrm{l}$. No significant difference of these parameters have been found between the soils where juncus acutus is located and other juncacea soils. The formation processes of this wetland and its high plants diversity make it singular in the Madrid aquifer context and constitute a unique enclave in Castilla-La Mancha.

Keywords: Wetland; Madrid aquifer; Henares river middle basin; indicative plants; hydrogeology; alkaline efflorescences; evaporation.

\section{Introducción y objetivos}

Los humedales del acuífero terciario detrítico de Madrid situados al oeste del río Jarama, la región básicamente constituida por las arcosas de la llamada "facies de Madrid" y ocupada por las Masas de Agua Subterránea (MASb en adelante) 030.10 "Manzanares-Jarama", 030-011 "Guadarrama-Manzanares", 030-012 "Aldea del Fresno-Guadarrama” y 030-015 "Talavera" (CHT, 2015) - que en conjunto forman la antigua Unidad Hidrogeológica (U.H.) "Madrid-Talavera" de SGOPITGE, (1990) -, fueron estudiados durante los años 80 del pasado siglo por ecólogos e hidrogeólogos de las universidades públicas madrileñas. Se realizó entonces un exhaustivo inventario y tipología genético-funcional de zonas húmedas en aquel territorio (González Bernáldez \& Montes, 1989; González Bernáldez et al., 1986; González Bernáldez et al., 1987) y se señaló la existencia de una estrecha relación de las características hidroquímicas de los suelos de estas áreas con las de las aguas subterráneas que los forman (Sastre et al., 1986).

Estos investigadores clasifican los humedales del acuífero en criptohumedales (descargas por evapotranspiración) y formaciones palustres y en relación sobre todo a los primeros, establecen grupos de especies de plantas que clasifican en función de su valor como indicadoras de una determinada salinidad (Herrera et al., 1987). Así, hablan de especies propias de agua dulce o glicófitas, asociadas a las descargas locales; de especies que se desarrollan en suelos con aguas alcalinas, o alcalinófilas, como
Juncus acutus y Hordeum secalinum que aparecen en las descargas regionales de este tipo de aguas; y finalmente de plantas indicadoras de la presencia de aguas subterráneas salinas o halófitas, entre las que destaca Juncus maritimus.

Al este del río Jarama, sobre la MASb 030.006 "Guadalajara", de carácter más arcilloso que la U.H. "Madrid - Talavera", en la región media de la cuenca terciaria del río Henares y alejado notablemente de las zonas de descarga regional del sistema, se desarrolla el Humedal de la Dehesa de Arriba, con notable presencia de plantas alcalinófilas y manifestaciones muy localizadas de salinización extrema del suelo, del que no existe hasta la fecha referencia alguna a su situación, origen hidrogeológico y posición relativa respecto del resto de zonas húmedas del acuífero (IGME-DGA, 2010). El objetivo fundamental de este trabajo es realizar una primera descripción del humedal y exponer una hipótesis sobre su origen y funcionamiento.

\section{Localización geográfica y contextos geológico e hidrogeológico}

El humedal de la Dehesa de Arriba, de 8 hectáreas de extensión, se encuentra a 718 m s.n.m. en la comarca de la Campiña Baja de la cuenca del río Henares, en la provincia de Guadalajara. Se sitúa en la cabecera del arroyo Camarmilla, afluente del río Henares por su margen derecha. Constituye el nacimiento del actual Camarmilla, ya que aporta agua a su cauce durante todo el año, y los arroyos de la Primera y Segunda Arroyada (Fig. 1), que son 


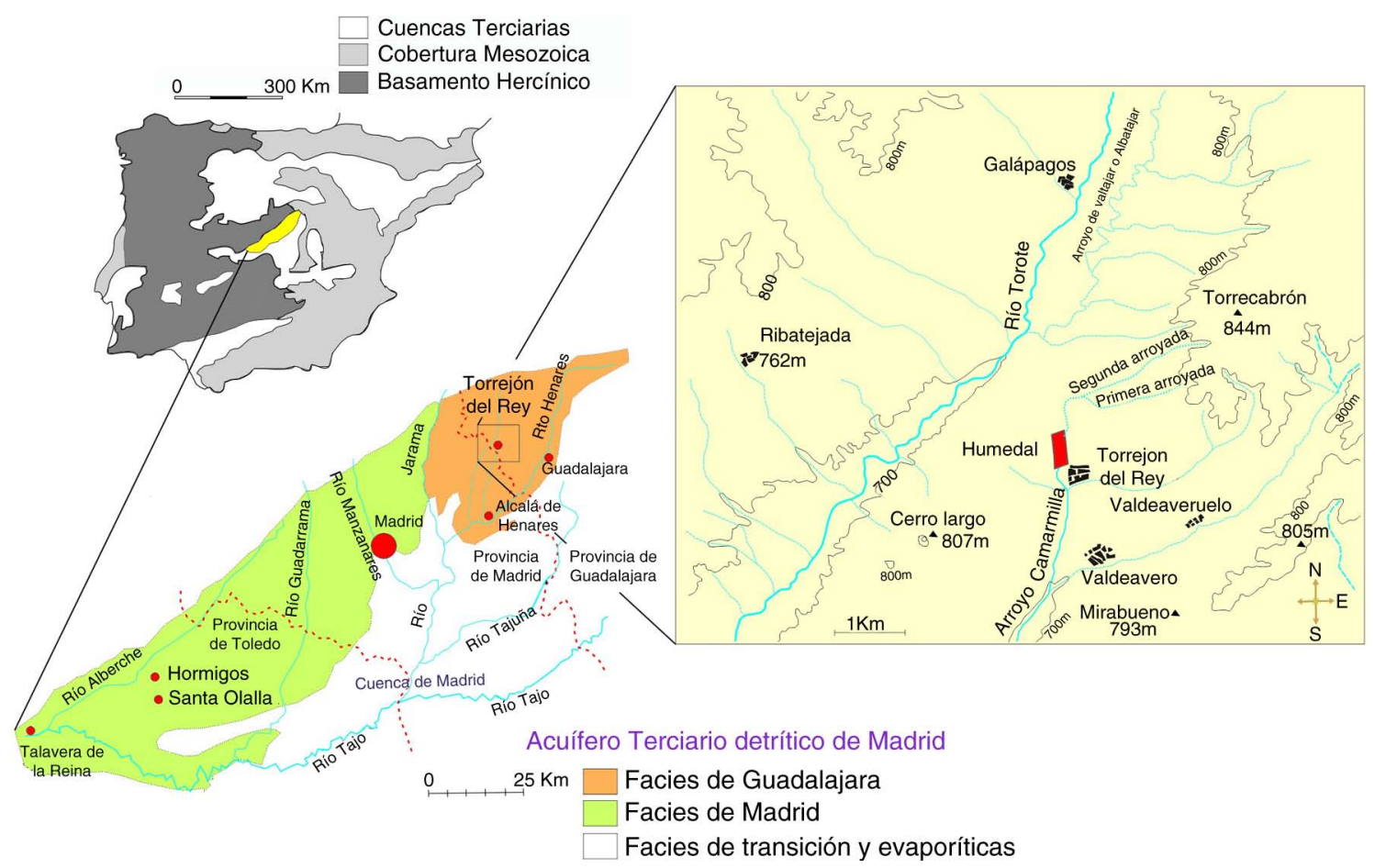

Fig. 1.- Mapa de localización del humedal de la Dehesa de Arriba en el acuífero de Madrid y red fluvial en sus alrededores.

geográficamente los cauces más alejados del punto de desembocadura del arroyo Camarmilla en el río Henares, en la localidad de Alcalá de Henares, son de carácter efímero. En la Figura 1 se puede observar su posición dentro del acuífero terciario detrítico de Madrid y localmente en el marco de la red fluvial actual, en la que destaca por su proximidad el arroyo Torote.

Las cuencas de los arroyos Torote y Camarmilla se extienden por los materiales detríticos miocenos de la MASb 030.006 "Guadalajara", más o menos coincidente con la antigua U.H. 03.04 "Guadalajara" de SGOP-ITGE (1990), formados por depósitos de arcosas feldespáticas, arenas arcillosas micáceas y limos arcillosos con un espesor aproximado de 480 metros (Villarroya, 1977; Pérez González et al., 1990; IGME-DGA, 2010). Estos materiales forman parte de los 2000 metros de relleno sedimentario que según Cadavid (1977) se encuentran en la vertical de esta zona de la cuenca terciaria del Tajo.

El flujo del agua en estos materiales, más activo en sus primeros 500 metros, se ajusta a las hipótesis de Hubbert (1940) y Toth (1962), de manera que existe una infiltración del agua de lluvia preferente en los interfluvios, con flujo vertical descendente en la zona saturada en esa franja, y una descarga en los valles, después de un recorrido variable, con flujo vertical ascendente. Se admite la existencia de flujos locales intracuenca, intermedios entre cuencas vecinas y regionales de mayor envergadura. La U.H. Guadalajara se describe, en virtud de su composición más arcillosa respecto a la U.H. Madrid-Talavera, como un material de menor permeabilidad en su conjunto, con valores de este parámetro de $0.22 \mathrm{~m} / \mathrm{d}$ (SGOP-ITGE, op . cit.), lo que debe tener influencia en el proceso de evolución hidroquímica del agua subterránea, siendo, para recorridos de semejante longitud, más efectivo el intercambio iónico $\mathrm{Ca}-\mathrm{Na}$, y mayor la salinidad, por ser mayor la permanencia del agua en contacto con el medio.

Se observa igualmente que existe una variación de la composición química del agua en estos materiales mayoritariamente detríticos, siendo de los interfluvios a los ríos, cada vez más clorurada, más sulfatada y menos bicarbonatada. Los yesos del centro de la cuenca, influyen en la hidroquímica del agua subterránea claramente; el humedal objeto de estudio se encuentra lejos de dicha influencia (Pérez González et al., 1990; Pérez González \& Portero García, 1990). 
Distintos autores, han identificado varios fenómenos de captura en la red fluvial de esta región, por adaptación a procesos de basculamiento del basamento. El más notorio de todos ellos es precisamente la captura del Camarmilla por el Torote (Royo y Gómez, 1928; Lázaro Ochaíta \& Asensio Amor, 1978; Vaudour, 1979), en el momento de deposición o inmediatamente después de la terraza $+8-20 \mathrm{~m}$, entre el Pleistoceno Medio y el Superior (Pérez González et al., 1990).

Morfológicamente el humedal se extiende por un valle asimétrico muy poco encajado, debido a depósitos de coluviones en su margen derecha, que elevan el suelo 2 metros respecto del punto más bajo en transversales E-O trazadas en su parte central (Figura 2), donde dominan los materiales aluviales de la llanura de inundación. El flujo eventual de los arroyos de la Primera y Segunda Arroyada (Figura 1) forma un pequeño valle que recorre la zona media. Así, el humedal se extiende por una superficie de morfología irregular donde coexisten áreas relativamente planas sobre los coluviones con otras en las que se define un valle de encajamiento imperceptible. Todo este sector en conjunto muestra una pendiente suave hacia el sur del $9 \%$.

\section{Material y métodos. Resultados obtenidos}

Se elaboró una cartografía de áreas de vegetación del humedal (Fig. 2) desde un punto de vista fisiognómico teniendo en cuenta las especies de mayor cobertura ( $>10 \%$ de cobertura) para cada área (Tabla 1). Para ello se realizó una fotointerpretación del humedal a partir de fotografía aérea. Durante los años 2010 y 2012, se realizaron numerosas salidas de campo en las estaciones de primavera, verano y otoño, con el fin de realizar labores de i) herborización y determinación de especies (Castroviejo et al., 1986-2013; Valdés et al., 1987; Blanca et al., 2011), ii) corrección de límites de las zonas cartográficas preestablecidas, y iii) estimación del número y cobertura de las especies presentes para cada zona cartográfica de vegetación registrada en el humedal.

Se identificaron 160 especies vegetales, 114 géneros y 36 familias botánicas. Se establecieron 22 áreas cartográficas, que se sintetizaron en un total de 5 áreas de vegetación (Figura 2) por coherencia fisiognómica y florística: 2 áreas con vegetación herbácea perenne de carácter glicófilo y subhalófilo, dominadas por juncales de gran porte, situadas a lo largo de la banda centro-este del humedal; 2 áreas de praderas de baja talla con especies de carácter glicófilo y subhalófilo, situadas principalmente en las bandas laterales este y oeste del humedal; 1 área con salgüeros (GonzálezBernáldez et al., 1986) con praderas halófilas, situada en el lateral oeste (Figuras 2 y 3); 1 área de vegetación nitrófila herbácea no dependiente de la humedad edáfica, en el noroeste del humedal; y por último una pequeña área de vegetación leñosa arbóreo-arbustiva (de carácter espinoso) al sudeste.

Para conocer el flujo subterráneo en el entorno regional del humedal se analizaron los mapas de isopiezas que aportan Villarroya en el año 1977 (Villarroya, 1977) y la CHT (CHT, 2002) según datos tomados en marzo-abril de 1997 de pozos con profundidades inferiores a $50 \mathrm{~m}$. El primero ha sido utilizado para realizar sobre él las estimaciones numéricas que son comentadas posteriormente. Reproducimos en la Figura 4 una síntesis de ambas cartografías en el entorno del humedal.

Para el estudio local de las características hidrológicas del humedal se realizó un inventario de puntos de agua (Tabla 2 y Figura 2) situados en las áreas de vegetación descritas y en las principales zonas geológicas definidas por Pérez González et al. (1990). Se realizaron 9 sondeos manuales con barrena de profundidad entre 0.4 y $1.45 \mathrm{~m}$ que fueron equipados con tubo ciego de PVC; la admisión del agua en ellos se producía por la base, que fue cubierta por una capa de grava para evitar la entrada de finos. Estos sondeos captan el agua subterránea en su nivel más elevado, dentro de la zona de evapotranspiración de los suelos. Completando el inventario se perforó un sondeo de 10 metros de profundidad (punto $\mathrm{n}^{\circ} 10$ Tabla 2 y Figura 2) y se incorporó un pozo particular.

La perforación de 10 metros se realiza con el objeto de obtener datos de la litología del sustrato, conocer el potencial hidráulico en profundidad y tomar muestras de agua representativas de la descarga subterránea al humedal y libre de los procesos de evapotranspiración. Su zona de admisión se limitó a sus dos últimos metros. Se realizaron en esta perforación 4 pruebas de permeabilidad en el sustrato Terciario que arrojaron una media de $1.5 \mathrm{~m} / \mathrm{d}$, un valor muy superior al aportado por SGOP-ITGE (1990). Se midió igualmente la granulometría de cada una de las unidades 


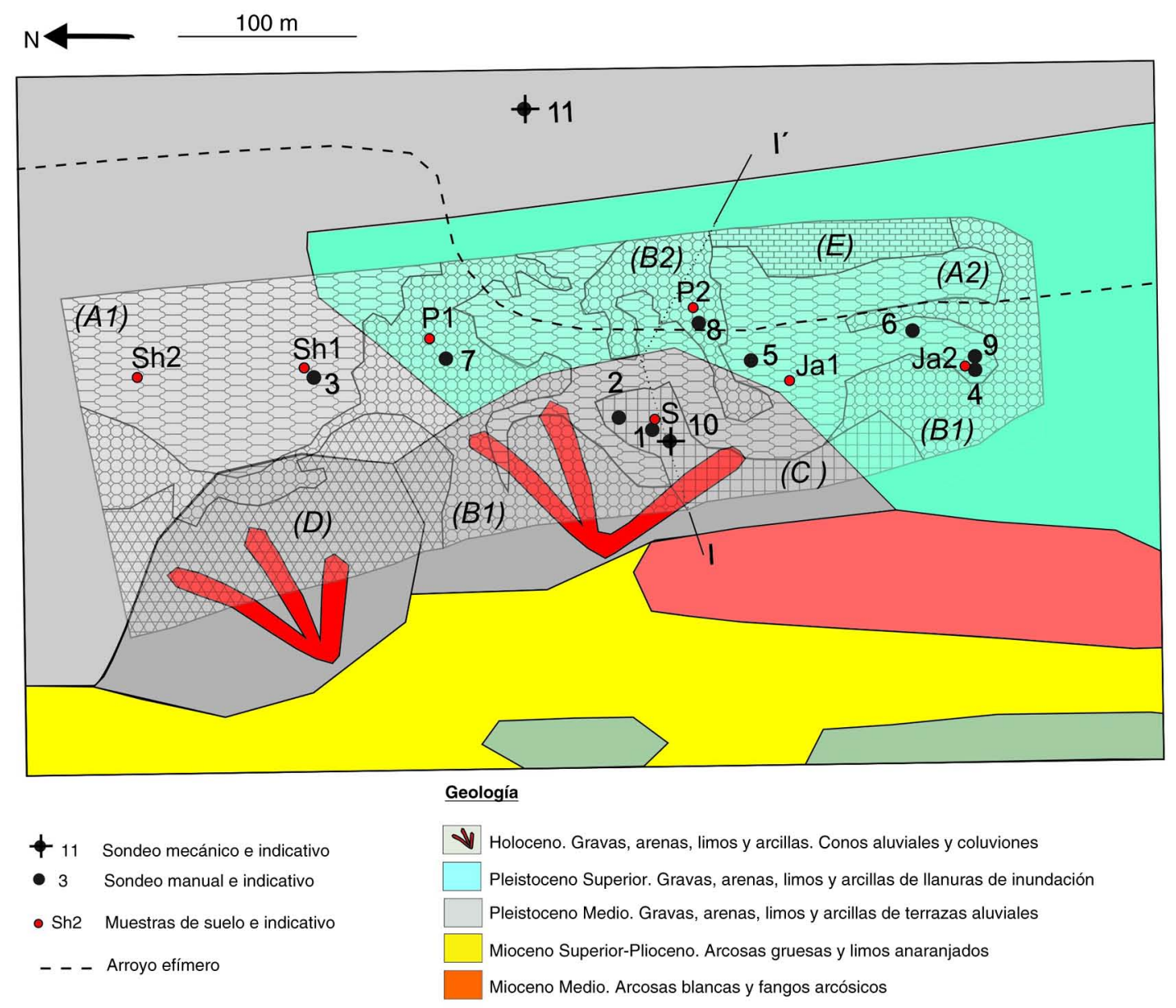

Áreas de vegetación
A
(A2)- Formación mixta de junco merino (Juncus acutus) con junco churrero

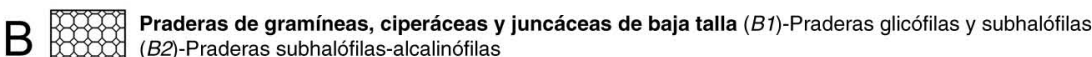
C \#\# Salgüeros con praderas halófilas
$\mathrm{D}$ Vegetación herbácea nitrófila (anuales y vivaces)
E Vegetación leñosa: olmedas, y espinosas (zarzales, rosales, espino albar)

Fig. 2.-Esquema geológico del humedal (modificado de Pérez González et al., 1990) y mapa de áreas de vegetación en el humedal. Se localizan los puntos de muestreo de suelos y el inventario de puntos de agua. Se señala el trazado del perfil de la Figura 5.

litológicas reconocidas en este sondeo cuyos resultados se muestran en la Figura 5 (Leyenda sondeo 10, en dicha figura).

En todos los puntos se tomaron medidas de profundidad del agua y se realizaron determinaciones en campo de conductividad eléctrica, $\mathrm{pH}$ y temperatura con equipos portátiles de la marca CRISON, al menos una vez al mes desde julio de 2012 a abril de 2013. Las medidas se realizaban directamente en la mayoría de los casos ya que el agua 
Tabla 1._Áreas cartográficas de vegetación. Para cada área se muestran las especies de mayor cobertura ( $>10 \%)$. Los símbolos que anteceden a algunas de las especies hacen referencia al carácter indiferente (-), glicófilo (+), subhalófiloalcalinófilo $\left(^{*}\right)$, y halófilo $\left.{ }^{* *}\right)$ de las mismas. Se señalaron con estos símbolos aquellas especies que aparecen así clasificadas en los humedales del acuífero de Madrid en González Bernáldez et al. (1989), a excepción de Hordeum marinum que aparece en este humedal

\begin{tabular}{|c|c|c|c|c|c|c|}
\hline \multicolumn{7}{|c|}{ Áreas de vegetación } \\
\hline \multicolumn{2}{|c|}{ A Juncales de gran porte } & \multicolumn{2}{|c|}{$\begin{array}{l}\text { B Praderas de gramíneas, ciperáceas y } \\
\text { juncáceas de talla baja }\end{array}$} & \multirow[b]{2}{*}{$\begin{array}{l}\text { C Salgüeros con } \\
\text { praderas halófilas }\end{array}$} & \multirow[b]{2}{*}{$\begin{array}{l}\text { D Vegetación } \\
\text { nitrófila }\end{array}$} & \multirow[b]{2}{*}{$\begin{array}{l}\text { E Vegetación } \\
\text { leñosa }\end{array}$} \\
\hline $\begin{array}{l}\text { A1-Juncal } \\
\text { churrero }\end{array}$ & $\begin{array}{l}\text { A2-Juncal } \\
\text { mixto }\end{array}$ & $\begin{array}{l}\text { B1-Praderas glicófilas y } \\
\text { subhalófilas }\end{array}$ & $\begin{array}{l}\text { B2-Praderas } \\
\text { subhalófilas- } \\
\text { alcalinófilas }\end{array}$ & & & \\
\hline $\begin{array}{l}\text { +Scirpoides } \\
\text { holoschoenus } \\
\text { Cynodon } \\
\text { dactylon }\end{array}$ & $\begin{array}{l}\text { *Juncus } \\
\text { acutus } \\
\text { +Scirpoides } \\
\text { holoschoenus }\end{array}$ & $\begin{array}{l}\text { Agrostis stolonifera }(<10 \%) \\
\text { Carex distans } \\
\text { Cirsium vulgare }(<10 \%) \\
\text { Cynodon dactylon } \\
\text { Brachypodium } \\
\text { phoenicoides }(<10 \%) \\
\text { Elytrigia pungens }(<10 \%) \\
\text { Elytrigia repens } \\
\text { Holcus lanatus }(<10 \%) \\
\text {-Carex divisa } \\
\text {-Poa trivialis }(<10 \%) \\
\text { + Agrostis castellana }(<5 \%) \\
\text { +Dactylis hispánica }(<10 \%) \\
\text { +Juncus articulatus }(<10 \%) \\
\text { +Juncus inflexus } \\
\text { *Festuca aundinacea } \\
\text { subsp. fenas }(<10 \%) \\
\text { *Hordeum secalinum } \\
\text { *Juncus gerardi }\end{array}$ & $\begin{array}{l}\text { Agrostis } \\
\text { stolonifera } \\
\text {-Carex } \\
\text { divisa } \\
\text {-Poa trivialis } \\
\text { *Festuca } \\
\text { aundinacea } \\
\text { subsp. fenas } \\
\text { *Hordeum } \\
\text { secalinum } \\
\text { *Juncus } \\
\text { gerardi }\end{array}$ & $\begin{array}{l}{ }^{* *} \text { Hordeum } \\
\text { marinum } \\
{ }^{* *} \text { Puccinelia } \\
\text { fasciculata } \\
{ }^{*} \text { Festuca } \\
\text { aundinacea } \\
\text { subsp. fenas } \\
{ }^{*} \text { Hordeum } \\
\text { secalinum } \\
\text { *Juncus gerardi } \\
\text {-Carex divisa } \\
\text { Cynodon } \\
\text { dactylon } \\
\text { Polypogon } \\
\text { monspeliensis }\end{array}$ & $\begin{array}{l}\text { Diversas especies } \\
\text { de gramíneas } \\
\text { de los géneros } \\
\text { Bromus, Avena, } \\
\text { Hordeum, Cirsium, } \\
\text { Taniatherum, } \\
\text { Elytrigia, con } \\
\text { Cynodon dactylon } \\
\text { Y compuestas } \\
\text { de los géneros: } \\
\text { Centaurea, Cirsium, } \\
\text { Onopordum, o } \\
\text { Sylibum }\end{array}$ & $\begin{array}{l}\text { Ulmus minor } \\
\text { Rubus } \\
\text { ulmifolius } \\
\text { Crataegus } \\
\text { monogyna } \\
\text { Rosa } \\
\text { micrantha }\end{array}$ \\
\hline
\end{tabular}

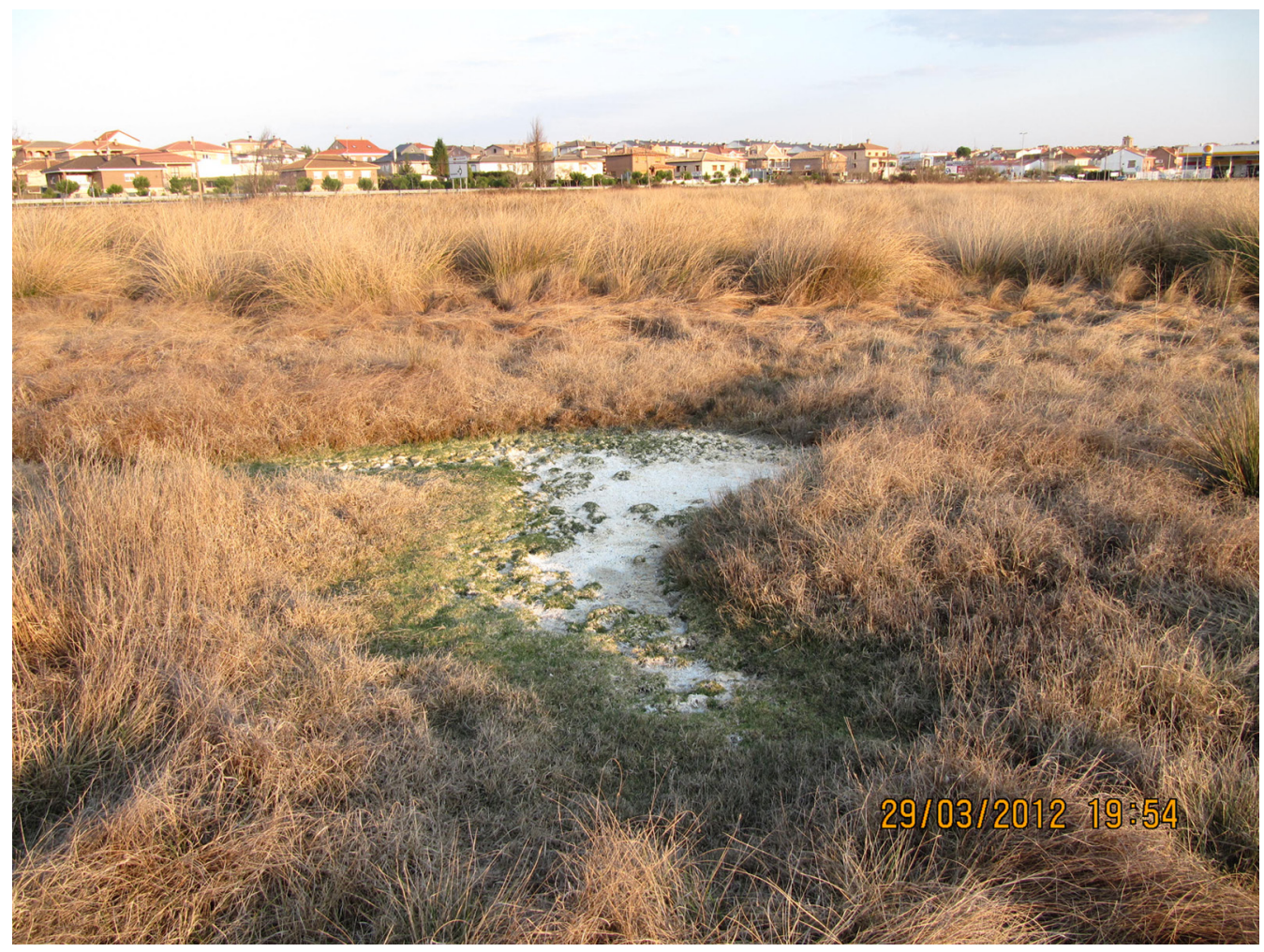

Fig. 3.-Fotografía del humedal de la Dehesa de Arriba. En primer término se observa uno de los numerosos salgüeros que se localizan en su lateral O. Al fondo, la localidad de Torrejón del Rey. 

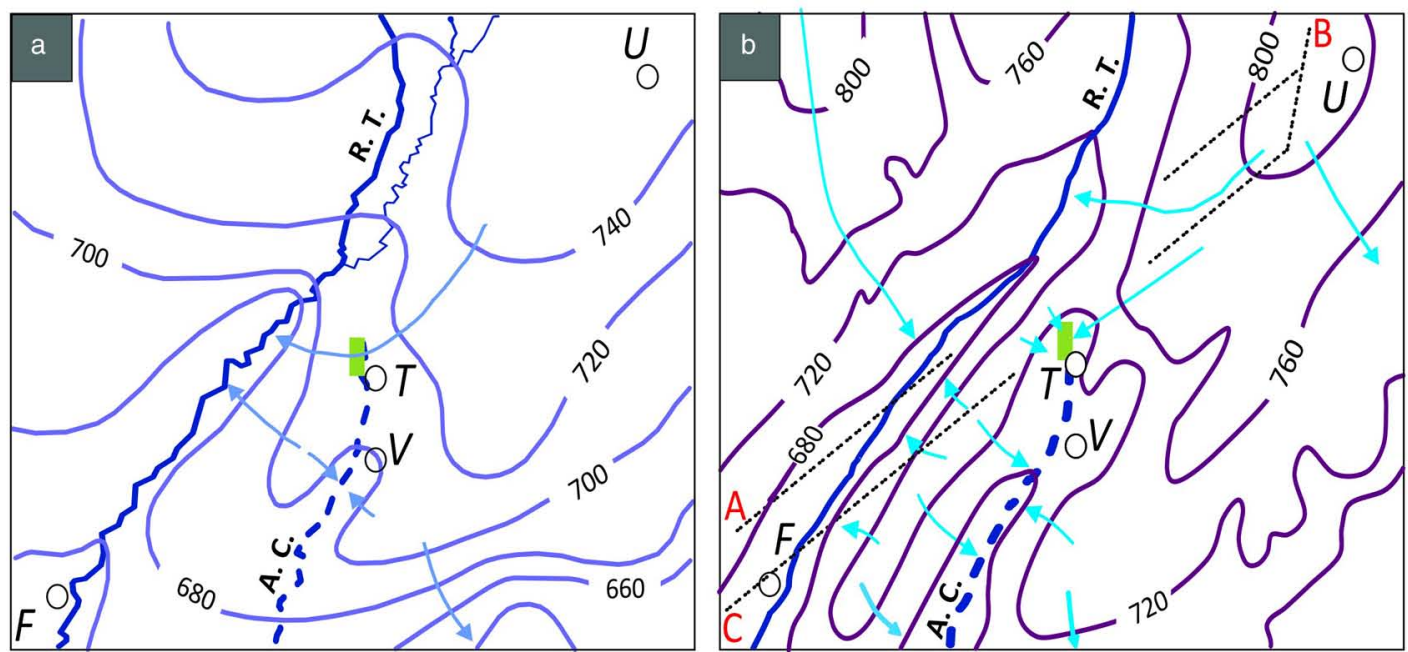

0 $4 \mathrm{~km}$
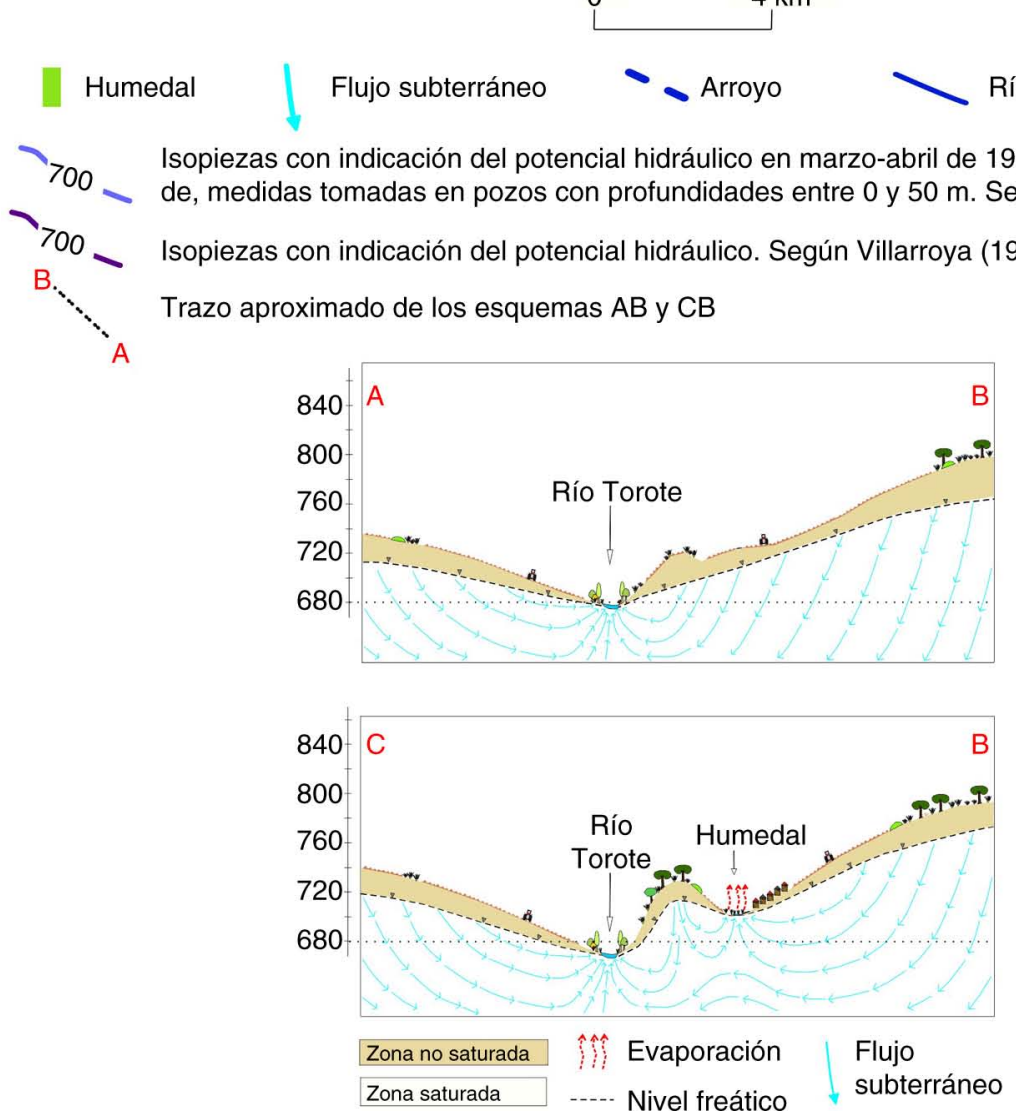

Fig. 4.-a. Mapa piezométrico (flujos locales) de la MASb Guadalajara en el entorno de Torrejón del Rey para marzo-abril de 1997 y según CHT (2002). b. Esquema de la superficie piezométrica en el mismo acuífero y entorno según Villarroya (1977). Se muestran los cortes esquemáticos $A B$ y $C B$.

subterránea se encontraba próxima a la superficie; en los puntos y/o momentos en los que se superaban los $60 \mathrm{~cm}$ de profundidad se extraía el agua con tomamuestras. Además se realizaron análisis hidrogeoquímicos completos en un laboratorio privado en el agua de los puntos 1, representativo del agua en los salgüeros, 8 representativo de las praderas de bajo porte, y 10 y 11 como representativos 
Tabla 2.--Inventario de puntos de agua del humedal. Áreas de vegetación nombradas según Tabla 1 y Figura 2

\begin{tabular}{|c|c|c|c|c|c|c|c|c|c|c|}
\hline \multirow[b]{2}{*}{$\mathrm{n}=$} & \multirow[b]{2}{*}{ Naturaleza } & \multirow[b]{2}{*}{ Área de Veg. } & \multirow[b]{2}{*}{ Prof. (m) } & \multirow[b]{2}{*}{ Cota } & \multicolumn{2}{|c|}{ UTM } & \multirow[b]{2}{*}{ USO } & \multirow[b]{2}{*}{$\mathrm{pH}$} & \multirow[b]{2}{*}{$\mathrm{T} \cong \mathrm{C}$} & \multirow[b]{2}{*}{ Con. $(\mu \mathrm{S} / \mathrm{cm})$} \\
\hline & & & & & $x$ & $\mathrm{Y}$ & & & & \\
\hline 1 & Perforación manual & $C$ & 0.4 & 719 & 471258.435 & 4500055.44 & Investigación & 8.89 & 12 & 11810 \\
\hline 2 & Perforación manual & C & 0.5 & 719 & 471260.59 & 4500082.92 & Investigación & 8 & 11 & 5310 \\
\hline 3 & Perforación manual & $A 1$ & 0.5 & 719 & 471272.982 & 4500223 & Investigación & & 11 & 1200 \\
\hline 4 & Perforación manual & $A 2$ & 0.45 & 716 & 471252.509 & 4499910.51 & Investigación & & 13 & 2938 \\
\hline 5 & Perforación manual & $A 2$ & 0.7 & 717 & 471262.745 & 4500007.49 & Investigación & & 12 & 1152 \\
\hline 6 & Perforación manual & $A 2$ & 1.4 & 716.5 & 471272.443 & 4499971.39 & Investigación & 7.5 & 11 & 1184 \\
\hline 7 & Perforación manual & $B 1$ & 1.1 & 718 & 471284.58 & 4500143.5 & Investigación & 6.9 & & 1030 \\
\hline 8 & Perforación manual & $B 2$ & 1.45 & 717 & 471297.2 & 4500006.69 & Investigación & 6.9 & & 1047 \\
\hline 9 & Perforación manual & $A 2$ & 1.3 & 716 & 471277.86 & 4499850.12 & Investigación & & & 1100 \\
\hline 10 & Sondeo & C & 10 & 719 & 471222.877 & 4500038.74 & Investigación & 7.6 & 10 & 743 \\
\hline 11 & Pozo perforado & $\ldots$ & 15 & 721 & 471421.681 & 4500100.16 & Privado & 7.74 & 10 & 714 \\
\hline
\end{tabular}

del agua subterránea que descarga en el humedal. Las muestras fueron recogidas en botellas de polipropileno y transportadas refrigeradas hasta el laboratorio, donde fueron analizadas en el transcurso de la primera semana tras su llegada. Todos los datos obtenidos se muestran en la Tabla 3 a la que añadimos los datos de dos puntos de agua, uno representativo de la zona de recarga en el material Terciario en el interfluvio Henares-Jarama (muestra A) y otro de la descarga regional del Terciario no influenciada por materiales yesíferos (muestra B).

Para conocer las características físicas del suelo, se recogieron 7 muestras de los primeros $30 \mathrm{~cm}$ en puntos distribuidos por las zonas de vegetación delimitadas sobre las que se realizó un análisis de textura y $\mathrm{pH}$. Su posición puede observarse en la Figura 2 y los resultados obtenidos se muestran en la Tabla 4.

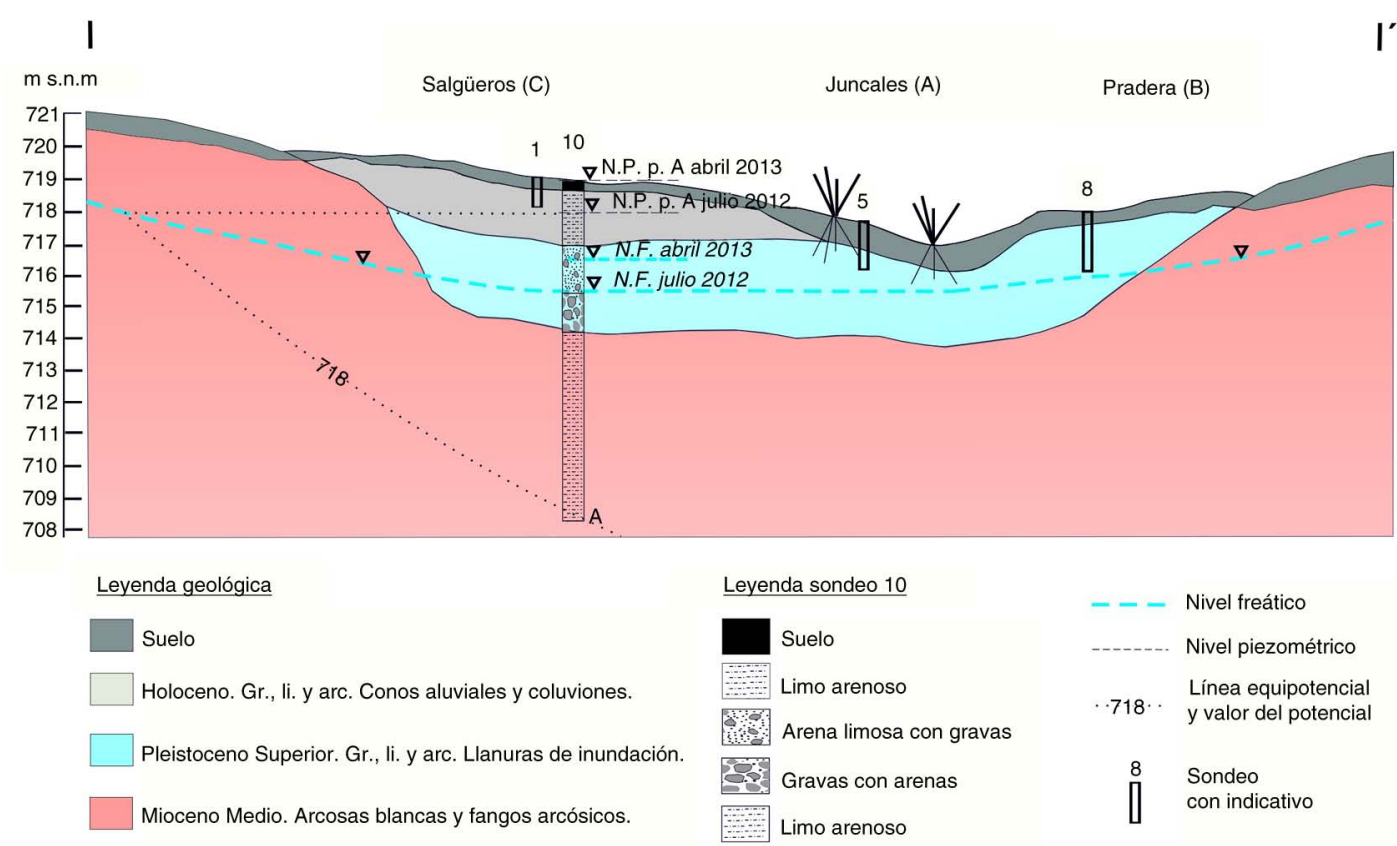

Fig. 5.-Esquema de funcionamiento hidrogeológico del humedal a través del corte esquemático l-I’ cuyo trazado se muestra en la Figura 2. Explicación en el texto. 


\begin{tabular}{|c|c|c|c|c|c|c|c|c|c|c|c|c|c|}
\hline \multirow{2}{*}{$\begin{array}{l}\mathrm{n}^{\circ} \\
\text { identificativo }\end{array}$} & \multirow[b]{2}{*}{ Zona de representación } & \multicolumn{9}{|c|}{$\mathrm{mg} / \mathrm{l}$} & \multirow[b]{2}{*}{$\mathrm{pH}$} & \multirow{2}{*}{$\begin{array}{c}\text { Con. } \\
(\mu \mathrm{S} / \mathrm{cm})\end{array}$} & \multirow[b]{2}{*}{ Error } \\
\hline & & $\mathrm{Cl}^{-}$ & $\mathrm{SO}_{4}^{-2}$ & $\mathrm{CO}_{3} \mathrm{H}^{-}$ & $\mathrm{CO}_{3}^{-}$ & $\mathrm{NO}_{3}^{-}$ & $\mathrm{Na}^{+}$ & $\mathrm{Mg}^{2+}$ & $\mathrm{Ca}^{2+}$ & $\mathrm{K}^{+}$ & & & \\
\hline 1 & Salgüeros & 2555.7 & 2392.4 & 909.9 & 138.1 & 0.5 & 2871.6 & 226.4 & 19.1 & 10.4 & 8.9 & 11810.0 & 2.32 \\
\hline 8 & Praderas & 80.2 & 121.2 & 567.4 & 0.0 & 0.7 & 106.7 & 32.5 & 126.1 & 0.3 & 6.9 & 1047.0 & -3.49 \\
\hline 10 & Descarga local humedal & 34.2 & 28.3 & 377.8 & 0.0 & 73.8 & 34.1 & 22.0 & 105.6 & 1.2 & 7.6 & 743.0 & -3.88 \\
\hline 11 & Descarga local humedal & 31.9 & 61.4 & 342.9 & 0.0 & 46.0 & 30.2 & 25.6 & 98.5 & 0.8 & 7.7 & 714.0 & -2.18 \\
\hline A & $\begin{array}{l}\text { Recarga Terciario } \\
\text { Henares }\end{array}$ & 35.4 & 125.0 & 280.0 & 0.0 & 3.6 & 26.0 & 24.3 & 88.1 & 2.2 & 7.3 & 640.0 & -8.41 \\
\hline B & $\begin{array}{l}\text { Descarga regional } \\
\text { Terciario Henares }\end{array}$ & 42.5 & 411.5 & 204.4 & 0.0 & 12.0 & 180.3 & 31.6 & 44.0 & 2.1 & 7.4 & 1113.0 & -4.76 \\
\hline
\end{tabular}

Tabla 4.--Resultados obtenidos en los análisis de suelo efectuados sobre muestras del humedal RP: Rango de profundidad muestra; T (USDA): Textura según Departamento de Agricultura de los Estados Unidos; F: Franco; A: Arcilloso; A: Arenoso

\begin{tabular}{|c|c|c|c|c|c|c|c|c|}
\hline \multirow[b]{2}{*}{ Muestra } & \multirow[b]{2}{*}{$\mathrm{RP}(\mathrm{m})$} & \multicolumn{3}{|c|}{ Granulometría (USDA) } & \multirow[b]{2}{*}{$\mathrm{T}(\mathrm{USDA})$} & \multirow[b]{2}{*}{ Salinidad } & \multirow[b]{2}{*}{$\mathrm{pH}$} & \multirow[b]{2}{*}{ Basicidad } \\
\hline & & Arcilla & Arena & Limo & & & & \\
\hline Sh1 & $0-0.30$ & 35 & 37 & 28 & FA & LS & 8.5 & B \\
\hline Sh2 & $0 .-0.30$ & 30 & 32 & 38 & FA & NS & 7.6 & $\mathrm{~N}$ \\
\hline Ja1 & $0-0.30$ & 35 & 41 & 24 & FA & LS & 8.8 & B \\
\hline Ja2 & $0 .-0.30$ & 29 & 48 & 23 & FAA & NS & 8.8 & B \\
\hline $\mathrm{P} 1$ & $0-0.30$ & 35 & 27 & 38 & FA & LS & 8.7 & B \\
\hline $\mathrm{P} 2$ & $0 .-0.30$ & 39 & 30 & 31 & FA & $S$ & 9.7 & B \\
\hline S & $0-0.30$ & 34 & 44 & 22 & FA & $\mathrm{S}$ & 10.3 & $\mathrm{~B}$ \\
\hline
\end{tabular}

\section{Análisis e interpretación de los resultados}

Los datos se analizan para conocer la procedencia y características de las aguas subterráneas que descargan en el humedal, para confeccionar un balance hídrico general y para elaborar una hipótesis que explique las razones de la variación de la salinidad de los suelos y la formación de salgüeros.

\section{Descarga de aguas subterráneas al humedal}

Según la disposición de las líneas isopiezas del entorno de Torrejón del Rey que aporta la CHT (CHT, 2002) para marzo-abril de 1997 (la fecha más reciente) deducida de medidas tomadas en pozos de entre 0 y $50 \mathrm{~m}$ de profundidad (flujos locales) y que reproducimos en la Figura 4a, el flujo subterráneo no descarga al humedal. Esta información no concuerda con las observaciones realizadas en el humedal en el marco de este trabajo a partir de las cuales deducimos un claro flujo de descarga del acuífero terciario incluso en periodos secos. El sondeo de 10 metros de profundidad realizado en el humedal (punto 10 Tabla 2), registró el nivel freático a $3.40 \mathrm{~m}$ de profundidad en julio de 2012. Después de la perforación completa del sondeo y de su equipamiento con rejilla de dos metros de longitud, situada en el fondo (a 708.5 m.s.n.m de altura), el nivel del agua se estabilizó 2.40 metros más arriba (Figura 5). Este ascenso refleja la condición de "valle" de este punto y certifica que efectivamente el desarrollo de esta zona húmeda se debe a la descarga de las aguas subterráneas del Mioceno detrítico. Para el tiempo en que se realizó el mapa de la CHT, el año hidrológico 1996/97, se registra una precipitación próxima a los $500 \mathrm{~mm}$ en el entorno de Guadalajara mientras que cuando se realizó el sondeo 10 , en el año 2011/2012, fue de $300 \mathrm{~mm}$ (datos de la AEMET), no 
existiendo entre un año hidrológico y otro grandes diferencias en la explotación del agua subterránea en el entorno de Torrejón del Rey. Por tanto, la tendencia a la descarga de agua subterránea al humedal desde el Terciario detrítico debe ser continua en condiciones de explotación y cantidad de lluvia recibida normales.

La configuración del mapa de la Figura 4a no muestra descarga subterránea al humedal de Torrejón del Rey en su fecha de referencia; el humedal se encuentra a 720 m s.n.m. y en dicho mapa, la isopieza de ese valor se localiza un kilómetro al Nordeste (ver Figura 4a). El trazado de dicha isopieza es por tanto erróneo a nivel local y este mapa no puede ser utilizado para realizar estimaciones del flujo de descarga.

En la misma fuente bibliográfica (CHT, 2002) puede consultarse otro mapa piezométrico de abril de 2000 configurado a partir de medidas realizadas en pozos de más de 50 metros de profundidad que no hemos añadido a la Figura 4a para no generar confusión; en este, el flujo subterráneo tiene una dirección NNO-SSE hacia el río Henares no descargando en el río Torote y obviamente tampoco al humedal.

Villarroya (1997) aporta un mapa piezométrico a partir del cual sí se puede deducir descarga subterránea al humedal (Ver Figura 4b), tanto desde la zona de Usanos (9 km al humedal) como desde el interfluvio Torote-Camarmilla ( $2 \mathrm{~km}$ al humedal). Pese a su carácter general y la fecha de sus datos, este mapa sirve para abordar el estudio de las características hidrológicas promedio del agua subterránea que descarga al humedal y ha sido por tanto el utilizado para realizar las estimaciones numéricas que serán comentadas más adelante.

En la transversal $\mathrm{AB}$ de la Figura 4 se observa que entre el humedal y el punto de captura del Camarmilla por el Torote, $2 \mathrm{~km}$ al norte, toda el agua subterránea procedente del entorno de Usanos, descarga en el río Torote, salvo la que logre alcanzar niveles profundos. La descarga al humedal se puede visualizar a través del esquema conceptual CB de la misma figura y del corte I-I'de la Figura 5 que refleja el comportamiento hidrogeológico del paraje a nivel local.

Se ha observado que existe un notable paralelismo entre las variaciones piezométricas en el sondeo 10 y las fluctuaciones del nivel freático de los sondeos manuales 5 y 6 de los que se tiene un registro continuo más prolongado (de julio de 2012 a abril de 2013) (Figura 6). Se aprecia igualmente que estas

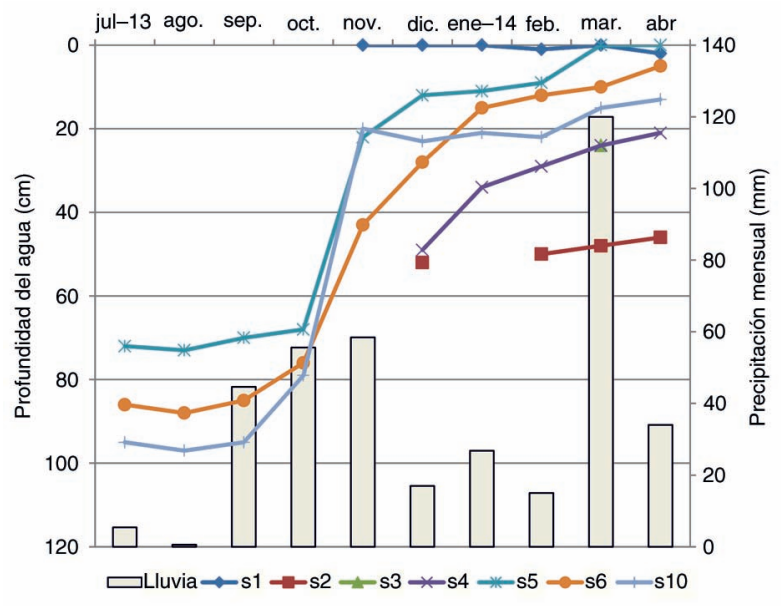

Fig. 6.-Medidas de las oscilaciones piezométricas en los sondeos de julio de 2012 a abril de 2013 y precipitación media mensual en el área.

oscilaciones siguen una importante concordancia con las precipitaciones. Estos hechos son compatibles con una recarga del agua subterránea relativamente próxima al humedal, como las indicadas a partir del análisis de la Figura 4b.

En relación a la hidroquímica, encontramos que las aguas subterráneas que descargan en el humedal (muestras 10 y 11, Tabla 3 y Figura 7), tienen unas características muy semejantes a las que se sitúan en las zonas de recarga del Terciario detrítico de la cuenca del Henares (muestra A Figura 7). El agua subterránea profunda en el humedal (muestras 10 y 11), mantiene la facies $\mathrm{CO}_{3} \mathrm{H}-\mathrm{Ca}$ y una mineralización próxima a los $700 \mu \mathrm{S} / \mathrm{cm}$, lo que es

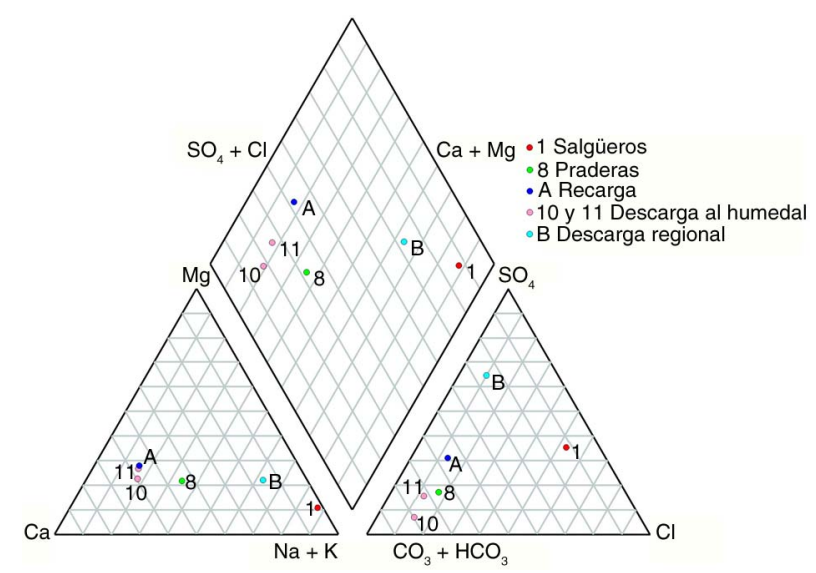

Fig. 7.-Diagrama de Piper con la representación de las muestras de la Tabla 3. 
compatible con un flujo corto en el contexto del acuífero Terciario. Por tanto, se producen en el humedal descargas de aguas subterráneas levemente evolucionadas. Es posible no obstante que el agua subterránea procedente del flujo más largo sí presente evolución hidrogeoquímica pero sea enmascarada por el agua subterránea procedente del interfluvio Camarmilla-Torote, de recorrido más corto.

El agua subterránea característica de las praderas es $\mathrm{HCO} 3-\mathrm{Ca}-\mathrm{Na}$ (muestra 8) y en los salgüeros Cl-SO4-Na (muestra 1), definiéndose una evolución del agua desde los puntos 10 y 11 al 1 por procesos de evaporación, tendencia muy distinta a la que se define entre los puntos 10 u 11 y el B (descarga regional) que se debe a un proceso de evolución natural con el flujo dentro del acuífero terciario.

Los valores de la conductividad en los sondeos manuales son en general más elevados que en el sondeo 10 y el pozo 11 lo que explicamos (ver Tabla 2) por estar el agua en los más superficiales afectada por procesos de concentración por evapotranspiración. Debemos indicar que el elevado valor de este parámetro en el sondeo $1(11810 \mu \mathrm{S} / \mathrm{cm})$ debe ser producto del lavado directo de las sales que se encuentran concentradas en los salgüeros por los continuos procesos de evaporación y la escasa capacidad de drenaje de sus suelos.

\section{Balance hídrico del humedal}

Las observaciones realizadas a lo largo del periodo de estudio, claramente diferencian la región donde se sitúan los salgüeros del resto de la superficie del humedal. Por esta razón se realiza por separado un balance hídrico medio (periodo de 1982 a 2012) para el conjunto de las 8 hectáreas del humedal, y un balance hídrico medio para el mismo periodo y exclusivo de las zonas con salgüeros, considerando que estas últimas constituyen únicamente el $6 \%$ de la superficie total.

Al no contarse con datos foronómicos del cauce del arroyo Camarmilla, por la dificultad de su obtención, aplicamos balances hidrometeorológicos de Thornthwaite y Matter (Custodio \& Llamas, 1983; Martínez de Azagra \& Navarro Hevia 1996) para obtener el valor anual de los componentes del ciclo hidrológico en el humedal. Utilizamos los datos de precipitaciones y temperaturas medias mensuales registrados de 1982 a 2012 en la estación "Guadalajara" de la Agencia Estatal de Meteorología (n³168 D) que posee una altitud semejante a Torrejón del Rey (720 m s.n.m.) y se encuentra a $15.8 \mathrm{~km}$ de distancia.

Para estimar el balance hídrico medio consideramos un comportamiento único en todo el humedal; tomamos como representativos del conjunto los parámetros edáficos de las áreas con juncales y las praderas por ocupar la mayor parte de la superficie estudiada. Sólo en la zona con salgüeros, de superficie reducida $\left(4600 \mathrm{~m}^{2}\right)$, se observa desecación durante el estiaje. Consideramos un espesor promedio de la zona de evapotranspiración de $0.5 \mathrm{~m}$ y suelos con texturas entre franco-arcillosa y franco-arcillosa-arenosa (Tabla 3) para los que hemos aplicado un valor $1.45 \mathrm{~g} / \mathrm{cm}^{3}$ de densidad aparente y una capacidad de campo del 25\% (NRCS-USDA, 2014). Estas estimaciones elevan la capacidad de campo de los suelos a $182 \mathrm{~mm}$. A las entradas en el balance por la precipitación se suman $58 \mathrm{~mm}$ mensuales procedentes de la descarga subterránea, que para las 8 hectáreas del humedal suponen $56400 \mathrm{~m}^{3}$ de agua $\left(48900 \mathrm{~m}^{3}\right.$ desde Usanos y $7500 \mathrm{~m}^{3}$ desde el interfluvio Torote-Camarmilla) que hemos deducido aplicando la ley de Darcy a tubos de flujo de longitud y anchura estimadas a partir de los esquemas de las Figuras 2 y $4 \mathrm{~b}$ y utilizando permeabilidades de $0.22 \mathrm{~m} / \mathrm{d}$ para el medio terciario (SGOP-ITGE, 1990); es posible que los $1.5 \mathrm{~m} / \mathrm{d}$ proporcionados por los ensayos realizados sean válidos muy localmente ya que con esa permeabilidad se obtienen volúmenes de agua inasumibles.

Con estos valores para los parámetros del balance general no se produce déficit hídrico en ningún momento del año (Figura 8a) lo que se ajusta a nuestras observaciones (a excepción de los salgüeros). Físicamente sucede que gracias a la entrada de agua por capilaridad desde el nivel freático en los meses más secos, los suelos asociados a estas zonas del humedal se pueden mantener con humedad (ver Figura 8a y Figura 5) o incluso pueden encontrarse dentro de la franja de la saturación capilar (Witlow 1994).

Esquematizamos el balance hídrico general del humedal también a través de la Figura $8 \mathrm{~b}$ con valores expresados en términos absolutos; en esta figura se incluye la entrada de la escorrentía anual generada por los $24000 \mathrm{~m}^{2}$ de superficie de los arroyos de la $1^{a}$ y $2^{a}$ Arroyada (Figura 1), que no influyen en toda la superficie ya que es agua que se canaliza naturalmente en la parte central. Se observa 
(a)

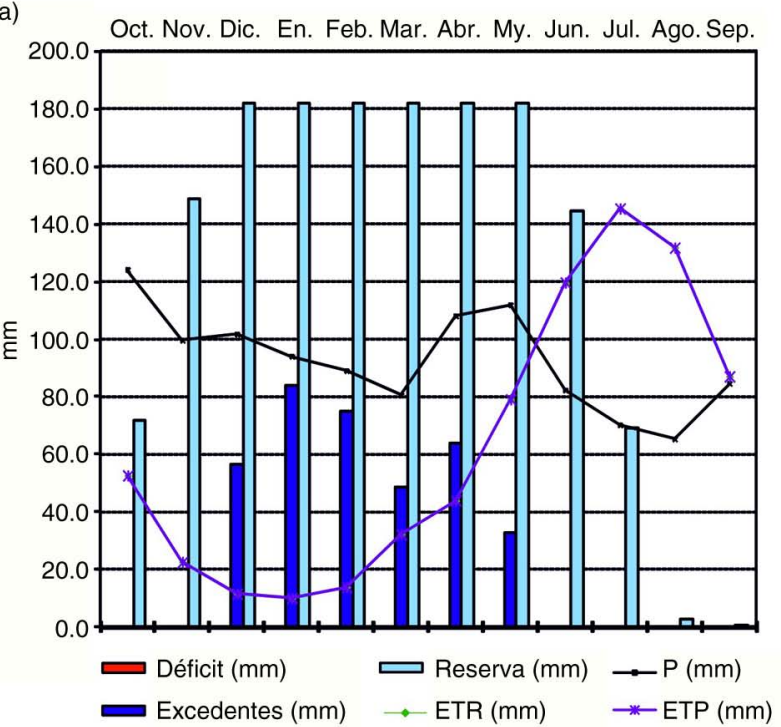

(b)

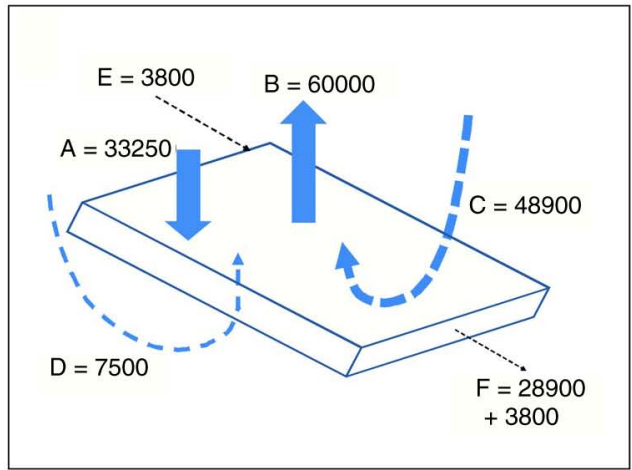

Fig. 8.-Balance hídrico anual medio (periodo 1982 a 2012) representativo del conjunto de la superficie del humedal expresado en mm (a) y en $\mathrm{m}^{3}$ /año (b). A: Precipitación; B: Evapotranspiración C: Descarga de agua subterránea procedente de la zona de Usanos; D: descarga desde interfluvio Torote-Camarmilla; E: escorrentía de los Ayos. de la $1^{\mathrm{a}}$ y $2^{\mathrm{a}}$ arroyada; F: escorrentía generada por el humedal.

que la escorrentía generada por el humedal y que se incorpora anualmente al arroyo Camarmilla es de $28900 \mathrm{~m}^{3}$ /año entre diciembre y mayo, a la que se sumarían $3800 \mathrm{~m}^{3}$ procedentes de los arroyos mencionados.

En el área con salgüeros (área $\mathrm{C}$ en Figura 2 y Tabla 1) el comportamiento es distinto y hemos realizado un balance hidrometeorológico ajustado a sus características. Allí los suelos son franco-arcillosos (Tabla 4), de hasta $0.3 \mathrm{~m}$ de espesor (menos por tanto que en el resto del humedal), y llegan a secarse completamente al final del verano (Figura 9). Considerando su descripción, se puede estimar una capacidad de campo de $140 \mathrm{~mm}$ en éstas áreas. Los resultados muestran un déficit hídrico en estas zonas próximo a los $50 \mathrm{~mm}$ anuales, que se produce en agosto y septiembre meses durante los cuales el nivel freático se encuentra más profundo y el flujo capilar llega con menor volumen a la zona de evapotranspiración (Figuras 5 y 6).

\section{Variaciones de la salinidad en los suelos del humedal y formación de salgüeros}

No existiendo fuentes geológicas de sales, las diferencias en la conductividad que existen entre el agua subterránea emergente al humedal en profundidad (pozos 10 y 11, Tabla 2) y la captada a nivel superficial (puntos del 1 al 9, Tabla 2) se deben a procesos de evapotranspiración. Así mismo, las diferencias de salinidad de los suelos entre unas zonas y otras del humedal (Tabla 4) se asocian a parámetros físicos, edáficos e hidrológicos que favorecen o dificultan su lavado y/o la disponibilidad de humedad. Así, los

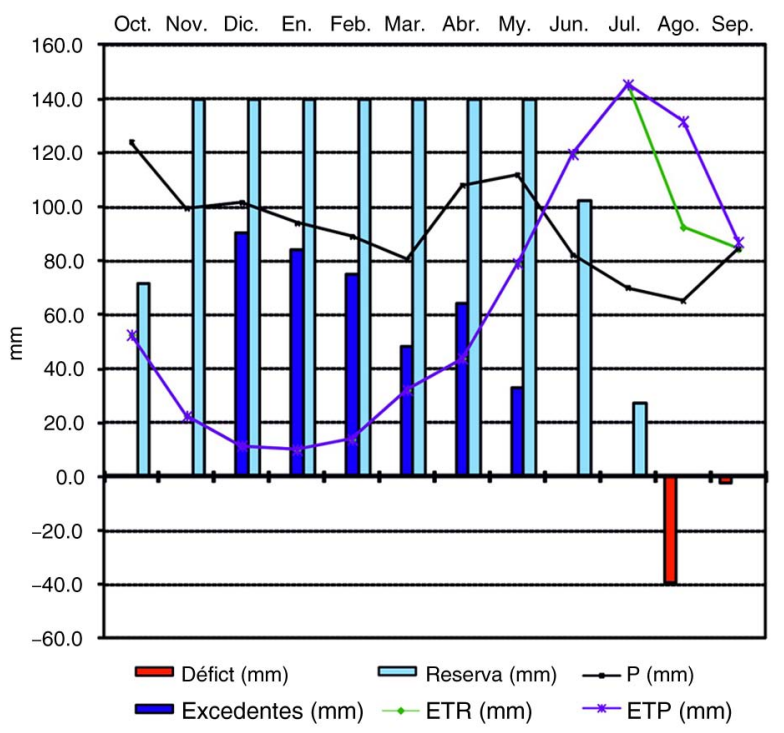

Fig. 9.-Balance hídrico anual medio (periodo 1982 a 2012) representativo del área con salgüeros ( $\mathrm{C}$ en Figura 2 ). 
salgüeros se desarrollan sobre superficies con escasa pendiente N-S en los coluviones y donde el nivel freático se encuentra más profundo (área de vegetación $\mathrm{C}$, ver Figuras 2 y 5), las praderas (área de vegetación B) se localizan fundamentalmente en los laterales del valle central sobre elevaciones menores y los juncales de gran porte (área de vegetación A) en el valle, con el nivel freático más alto y con mayor influencia de las aguas superficiales (Figura 5).

Los suelos en el humedal poseen una textura franco arcillosa y en su zona central franco arcilloso-arenosa (Tabla 4). Y se forman sobre sustratos de distinta naturaleza entre limos arenosos y limos arcillosos, en los coluviones, y gravas y limos arcilloso-arenosos en el resto del humedal (área de vegetación A). Teniendo en cuenta el predominio de los limos en el sustrato y la abundancia de arcillas en los suelos, podemos estimar una altura máxima de ascenso capilar en todas las áreas de entre $4 \mathrm{y}$ 6 m (Custodio \& Llamas, 1983; Das, 1998). La proximidad del nivel freático en las zonas centrales del humedal donde predominan los juncales de gran porte (área A) garantiza la humedad en los suelos durante todo el año, bien directamente o por aporte capilar mientras que a la superficie de las áreas laterales con predominio de las praderas (área de vegetación B) y especialmente en la zona con salgüeros situados sobre coluviones (área $\mathrm{C}$ ) sólo llega el agua capilar (donde rápidamente es evaporada o evapotranspirada) que además lo hará a menor velocidad en verano cuando el nivel freático se encuentre más bajo (Das, 1998) creándose así unas condiciones propicias para la concentración de sales por evaporación (Figura 5).

Por lo tanto, los procesos de concentración salina en el agua del suelo por evaporación son, en las zonas con juncales de gran porte, moderados, aunque pueden explicar la presencia de determinados elementos como el $\mathrm{Na}$ en concentraciones tales que favorezcan el desarrollo de especies tolerantes a los mismos; en las praderas de bajo porte acusados, y en los salgüeros, mayor.

En las áreas de descarga regional del acuífero de Madrid (González Bernáldez \& Montes, 1989), aparecen salgüeros con notable frecuencia; quizás la más representativa de estas áreas sea la zona de Maqueda-Santa Olalla-Hormigos (Figura 1), por su gran extensión y por la gran cantidad de salgüeros que presenta; allí las aguas subterráneas tienen un contenido en Na entre 30 y 80 meq/1 (González Bernáldez et al., 1986). Sin embargo las aguas subterráneas que llegan al humedal de Torrejón son de descarga local, aguas que evolucionan tras un recorrido de apenas $10 \mathrm{~km}$ por el acuífero, con contenidos de $\mathrm{Na}$ de $1.4 \mathrm{meq} / 1$. En ambos casos los procesos de evaporación son los responsables de la concentración de sales en superficie, pero en Torrejón del Rey se parte de un agua mucho más diluida.

\section{Discusión y conclusiones}

El origen del humedal está asociado al proceso de captura del Camarmilla por el Torote. Es razonable pensar que el humedal representa el primer punto al sur de la captura donde el valle del Camarmilla capta aguas subterráneas ya que se encuentra lo suficientemente separado para ello del río Torote. Entre el humedal y el punto de captura toda el agua subterránea llega al río Torote ya que éste circula cerca del valle "muerto" del Camarmilla y mucho más encajado. Este proceso ha debido ser progresivo ya que tras la captura superficial, el Torote ganó caudal y capacidad de encajamiento frente al valle del Camarmilla.

La descarga subterránea en donde ahora está situado el humedal existió antes de la captura pero tras esta, ya no se produce a un cauce bien definido. El valle "muerto", va suavizando sus laderas adquiriendo una morfología de suaves pendientes. El hecho de que los coluviones depositados en el lado oeste del humedal (Fig. 2 y 4) y que ocupan un tercio de su superficie no se hayan desmantelado es consecuencia de este proceso. Si la captura no se hubiera producido el humedal no tendría la extensión y apariencia que presenta hoy, ya que el Camarmilla se hubiera encajado, como el resto de la red, asimilando y desaguando por su cauce las aguas de descarga, manifestando una menor diversidad vegetal respecto a la actual.

El encajamiento que sufre de manera generalizada la red de drenaje de la cuenca del Tajo al final del Terciario, se vio abortado en el caso del Camarmilla debido a su captura por el Torote, lo que provocó la aparición de un humedal con una dinámica diferente a la de la mayoría de las zonas húmedas del acuífero de Madrid, en el que coexisten praderas, sectores con juncales de diversos tipos y un área con salgüeros. 
Sastre et al. (1986) indican la existencia de una fuerte correlación entre la química del agua subterránea y la del suelo de los humedales del acuífero de Madrid, que se produce precisamente por el fuerte encajamiento de la red fluvial. Al no concurrir esta circunstancia en el humedal de la Dehesa, en las zonas con grandes juncales la concentración mineral del agua en la zona de evapotranspiración se aproxima sólo parcialmente a la del agua subterránea emergente, y en las praderas de bajo porte y especialmente en los salgüeros las diferencias son notables. En todos los casos, dichas diferencias se deben a variaciones de la intensidad de los fenómenos de evaporación provocadas por la distancia entre el nivel freático y la superficie. Tanto las praderas como los salgüeros se encuentran en áreas laterales del humedal y no influenciadas por el valle central donde se produce mayor drenaje y el nivel freático se encuentra más próximo a la superficie. Y es precisamente en estas áreas donde mayor cantidad de juncáceas existen. Parece evidente que el microrelieve del humedal juega un papel importante en la distribución de las especies vegetales considerando que a toda la superficie llega agua subterránea de la misma naturaleza.

En el contexto del acuífero de Madrid, este humedal es singular considerando su posición alejada de las áreas de descarga regional. Su particular génesis y funcionamiento origina una alta y valorable diversidad vegetal, con presencia de Hábitats de Importancia Comunitaria incluso de carácter Priorizado (de la Unión Europea) y Hábitats de Especial Conservación para la región de Castilla-La Mancha (Martín Herrero et al., 2003), y fenómenos de interés de indudable valor. Este humedal con su particular vegetación asociada, se añadiría como una novedad tipológica al listado de lagunas y humedales de la provincia de Guadalajara definido por Medina (2003). Su conservación debe constituir un elemento prioritario en las políticas ambientales locales y regionales.

\section{AGRADECIMIENTOS}

Agradecemos la colaboración del Ayuntamiento de Torrejón del Rey (Guadalajara) que ha posibilitado la realización de este trabajo, especialmente a la Concejalía de Medio Ambiente, a Eduardo Colubi como responsable del programa Agenda 21 Local y a Vidal Gómez Leciñana como Guarda de campo del municipio.

\section{Referencias}

Blanca, G.; Cabezudo, B.; Cueto, M.; Salazar C. \& Morales Torres C. (2011). Flora Vascular de Andalucía Oriental. Universidades de Almería, Granada, Jaén y Málaga. $1751 \mathrm{pp}$.

Cadavid, S. (1977). Mapa estructural del techo del basamento del borde meridional de la Sierra de Guadarrama. Boletín Geológico y Minero, 88 (6): 494- 496.

Castroviejo, S. (1986-2013). Flora ibérica 1-8, 10-15, 17-18, 20-21. Real Jardín Botánico, CSIC, Madrid. Disponible en: http://www.floraiberica.org/

CHT (2002). Normas para el otorgamiento de autorizaciones de investigación o concesiones de agua subterránea para cada Unidad Hidrogeológica de la cuenca del Tajo. Confederación Hidrográfica del Tajo. Madrid.

CHT (2015). Mapa general de localización de Masas de Agua Subterránea de la cuenca del Tajo. Web de la CHT. Disponible en: http://www.chtajo.es/

Custodio, E. \& Llamas, M.R. (1983). Hidrología Subterránea. Omega, Barcelona, 1194 pp.

Das, B.M. (1998). Principles of Geotechnical Engineering. PWS Publishing Company, 726 pp.

González Bernáldez, F.G. \& Montes, C. (1989). Los humedales del acuífero de Madrid. Inventario y Tipología basada en su Origen y Funcionamiento. Canal de Isabel II, 92 pp.

González Bernáldez, F.G.; Herrera, P.; Levassor, C.; Peco, B. \& Sastre, A. (1987). Las aguas subterráneas en el paisaje. Investigación y Ciencia, 127: 8-17.

González Bernáldez, F.G.; Herrera, P. \& Montes, C. (1986). Los volcanes de barro o salsas. Fenómenos hidrogeológicos de interés ecológico. Anales de Biología, 12: 3-9.

Herrera, P.; González Bernáldez, F.G.; Levassor, C. \& Peco, B. (1987). Plantas indicadoras de características químicas del acuífero de Madrid: aguas subterráneas. Hidrogeología y Recursos Hidráulicos, 11: 65-87.

Hubbert, M.K. (1940). The theory of groundwater motion. Journal of Geology, 48 (8): 785-944. http://dx.doi. org/10.1086/624930

IGME-DGA (2010). Actividad 4. Identificación y caracterización de la interrelación que se presenta entre aguas subterráneas, cursos fluviales, descargas por manantiales, zonas húmedas y otros ecosistemas naturales de especial interés hídrico. Demarcación hidrográfica 031 Tajo. Masa de Agua Subterránea 031.006 Guadalajara. Instituto Geológico y Minero, 51 pp.

Lázaro Ochaita, I. \& Asensio Amor, I. (1978). La raña, glacis encajados y terrazas al NE de Madrid (Estudio Geomorfológico). Estudios Geológicos, 34: 45-51.

Mártinez de Azagra, A., \& Navarro Hevia, J. (1996). Hidrología forestal. El ciclo hidrológico. Secretariado de Publicaciones de la Universidad de Valladolid, Valladolid, 286 pp. 
Martín Herrero, J.; Cirujano Bracamonte, S.; Moreno Pérez, M.; Peris Gisbert, J.B. \& Stübing Martínez, G. (2003). La vegetación Protegida en Castilla-La Mancha. Junta de Comunidades de Castilla-La Mancha, 375 pp.

Medina Domingo, L. (2003). Flora y vegetación acuáticas de las lagunas y humedales de la provincia de Guadalajara (Castilla-La Mancha). Universidad Autónoma de Madrid, Facultad de Ciencias. Tesis Doctoral, 404 pp.

NRCS-USDA (2014). Clases texturales del suelo y densidad aparente. Natural Resources Conservation Services, United States Department of Agriculture. Disponible en: http://www.nrcs.usda.gov

Pérez González, A.; Aznar, J.M.; Díaz, M. \& Gallardo, J. (1990). Cartografía y memoria del mapa geológico de Algete, 1:50.000, $\mathrm{n}^{\circ}$ 535. ITGE. Madrid.

Pérez González, A. \& Portero García, (1990). Cartografía y memoria del mapa geológico de Alcalá de Henares, 1:50.000, $\mathrm{n}^{\circ}$ 560. ITGE. Madrid.

Royo y Gómez, J. (1928). El Terciario continental de la Cuenca Alta del Tajo. In: Datos para el estudio de la Geología de la provincia de Madrid. IGME, Madrid, 17-89.

Sastre,A.; Hidalgo,A.J.; Herrera, P. \& González Bernáldez, F. (1986). Correlaciones agua subterránea-suelo en los humedales de Madrid. Jornadas de explotación de aguas subterráneas en la Comunidad de Madrid. Canal de Isabel II. PIAM, 12: 155-169.

Servicio Geológico de Obras Públicas-Instituto Geológico Geominero de España (1990). Unidades Hidrogeológicas de la España peninsular e Islas Baleares. Síntesis de sus características y mapa a escala 1:1.000.000. Boletín de investigaciones y estudios del SGOP, 52.

Toth, J. (1962). A theory of groundwater motion in small drainage basins in Central Alberta, Canada. Journal of Geophysical Research, 67 (11): 4372-4387. http:// dx.doi.org/10.1029/JZ067i011p04375

Valdés, B.; Talavera, S. \& Fernández-Galiano, E. (1987). Flora Vascular de Andalucía Occidental. Volúmenes I, II, III. Ketres Editora, Barcelona, 1680 pp.

Vaudour, J. (1979). La region de Madrid, alterations, sols et paleosols. Ophys. 390 pp.

Villarroya, F.I. (1977). Hidrogeología regional del Neógeno detrítico y el Cuaternario de la Cuenca del río Henares. Tesis Doctoral. Facultad de Ciencias Geológicas, Universidad Complutense de Madrid. 745 pp.

Whitlow, R. (1994). Fundamentos de Mecánica de Suelos. Compañía Editorial Continental. 589 pp. 